\title{
Systematized Epidermal Nevus Syndrome Involving the Upper and Lower Eyelids Bilaterally
}

\author{
(1) Özlem Biçer*, (1) Ayşe Boyvat**, (1) Melek Banu Hoşal***, (1) Cevriye Cansız Ersöz****, \\ (D) Aylin Okçu Heper**** \\ *Boğazlıyan State Hospital, Clinic of Ophthalmology, Yozgat, Turkey \\ **Ankara University Faculty of Medicine, Department of Dermatology, Ankara, Turkey \\ ***Ankara University Faculty of Medicine, Department of Ophthalmology, Ankara, Turkey \\ ****Ankara University Faculty of Medicine, Department of Pathology, Ankara, Turkey
}

\begin{abstract}
A 29-year-old woman presented with dark-colored raised lesions on both eyelids since early childhood. Ophthalmological examination revealed pigmented verrucous lesions on her upper and lower eyelids bilaterally. The patient had a history of generalized tonic-clonic seizures. Dermatological examination revealed hyperpigmented verrucous plaques arranged along lines of Blaschko on the neck, trunk, and arms. On the basis of these findings, the diagnosis of epidermal nevus syndrome (ENS) was made. She had surgery for debulking of the lesions. Histological analysis revealed hyperkeratosis with foci of parakeratosis, acanthosis, and papillomatosis, consistent with linear verrucous epidermal nevus. Postoperative residual lesions did not respond to oral acitretin therapy ( $10 \mathrm{mg} / \mathrm{kg} / \mathrm{day}$ for $2 \mathrm{months}$ ). Systematized ENS can rarely cause linear verrucous nevi on the upper and lower eyelids on both sides. These patients should be investigated for accompanying systemic anomalies and followed for potential malignant transformation of the skin lesions.
\end{abstract}

Keywords: Epidermal nevus, epidermal nevus syndrome, eyelid, linear verrucous epidermal nevus

\section{Introduction}

Epidermal nevi (EN) are cutaneous hamartomatous lesions derived from the embryonic ectoderm and characterized by hyperplasia of the epidermis and adnexal structures. Epidermal nevus syndrome (ENS), first described by Schimmelpenning in 1957 , is a neurocutaneous disorder characterized by the presence of EN in association with various developmental nervous, ocular, skeletal, cardiovascular, and urogenital abnormalities. ${ }^{1,2} \mathrm{EN}$ usually show a linear pattern along the Blashko lines and are categorized as systematized when they involve large areas on either side of the body.

Here, we report a rare case of systematized ENS causing linear verrucous EN in both upper and lower eyelids bilaterally.

\section{Case Report}

A 29-year-old woman presented with the complaint of darkcolored raised lesions on both eyelids since early childhood. At the age of 7 years, the plaques on her eyelids had become more raised, verrucous, and scaly. Her medical history was significant for generalized tonic-clonic seizures starting in early childhood. The seizures were well controlled with anti-epileptics including carbamazepine $(800 \mathrm{mg} /$ day) and lamotrigine $(200 \mathrm{mg} /$ day $)$. There was no evidence of mental retardation in the patient. Her family history was unremarkable.

Ophthalmological examination revealed pigmented verrucous lesions on her upper and lower eyelids bilaterally (Figure 1a). Her visual acuity was 20/20 in both eyes. Slit-

\footnotetext{
Address for Correspondence: Özlem Biçer, Boğazlıyan State Hospital, Clinic of Ophthalmology, Yozgat, Turkey E-mail: ozlembicer90@gmail.com ORCID-ID: orcid.org/0000-0002-7638-4739 Received: 18.10.2020 Accepted: 03.05.2021
}

Cite this article as: Biçer Ö, Bovyat A, Hoşal MB, Cansız Ersöz C, Okçu Heper A. Systematized Epidermal Nevus Syndrome Involving the Upper and Lower Eyelids Bilaterally. Turk J Ophthalmol 2021;51:243-245

${ }^{\circ}$ Copyright 2021 by Turkish Ophthalmological Association Turkish Journal of Ophthalmology, published by Galenos Publishing House. 
lamp and fundus examinations were normal. Dermatological examination revealed hyperpigmented verrucous plaques arranged along lines of Blaschko with areas involving the neck, trunk, and arms (Figure 1b, c). No pathological findings were observed in the musculoskeletal, urogenital, and cardiovascular systems. Palliative debulking of the eyelid lesions was performed for cosmetic reasons.

Histologic examination was compatible with EN (Figure 1d). The patient was diagnosed with ENS due to the history of epilepsy accompanying the extensive EN. The patient was treated with systemic oral $10 \mathrm{mg} / \mathrm{kg} /$ day acitretin therapy but the drug was discontinued after two months because the lesion showed no reduction in size (Figure 1e).

\section{Discussion}

EN are rare hamartomas that usually appear at birth but may become clinically observable later in life. ${ }^{3} \mathrm{EN}$ are classified according to their clinical appearance as solitary or localized linear lesions, systematized (bilateral, parallel linear lesions), nevus unius lateralis (unilateral lesions), and ichthyosis hystrix (bilateral and symmetric involvement). ${ }^{4}$ Our case was evaluated as systematized EN with many verrucous plaques located on the patient's neck, trunk, and extremities and oriented along the
Blaschko lines. The incidence of ENS is 1 in 1,000 newborns. Sporadic cases are more common than familial ones. ${ }^{3}$

The prevalence of ocular involvement in ENS is estimated to be $9-70 \%$., $\mathrm{EN}$ may occur in the eyelid or conjunctiva. Associated abnormalities may include ocular coloboma, epibulbar choristomas or lipodermoids, and corneal opacities. ${ }^{5,6}$ Other rare associations are strabismus, ptosis, microphthalmia, nystagmus, astigmatism, cataract, and bilateral tear duct obstruction. ${ }^{7}$ Our patient had linear verrucous EN on her eyelids bilaterally without any other ocular abnormality. Bilateral EN of the eyelids have been previously described only once, in a systematized cutaneous case without any extraocular abnormalities. ${ }^{8}$ An extensive four-eyelid blepharoplasty and anterior lamellar rotation of the eyelashes were performed for treatment.

Café-au-lait macules, cutaneous hemangiomas, acanthosis nigricans, and melanocytic nevi are other dermatological findings that can be seen in ENS. ${ }^{9}$ Neurologic abnormalities have been described in up to $50-70 \%$ of patients with ENS and include mental retardation, seizure, hypotonia, hyperkinesia, hemiplegia, hemiparesis, and cranial nerve palsies., ${ }^{9,10}$ Skeletal anomalies occur in approximately $50 \%$ of patients with ENS (e.g., kyphoscoliosis, congenital hip dislocation, vitamin D-resistant rickets, limb hypertrophy, syndactyly, polydactyly, clinodactyly,
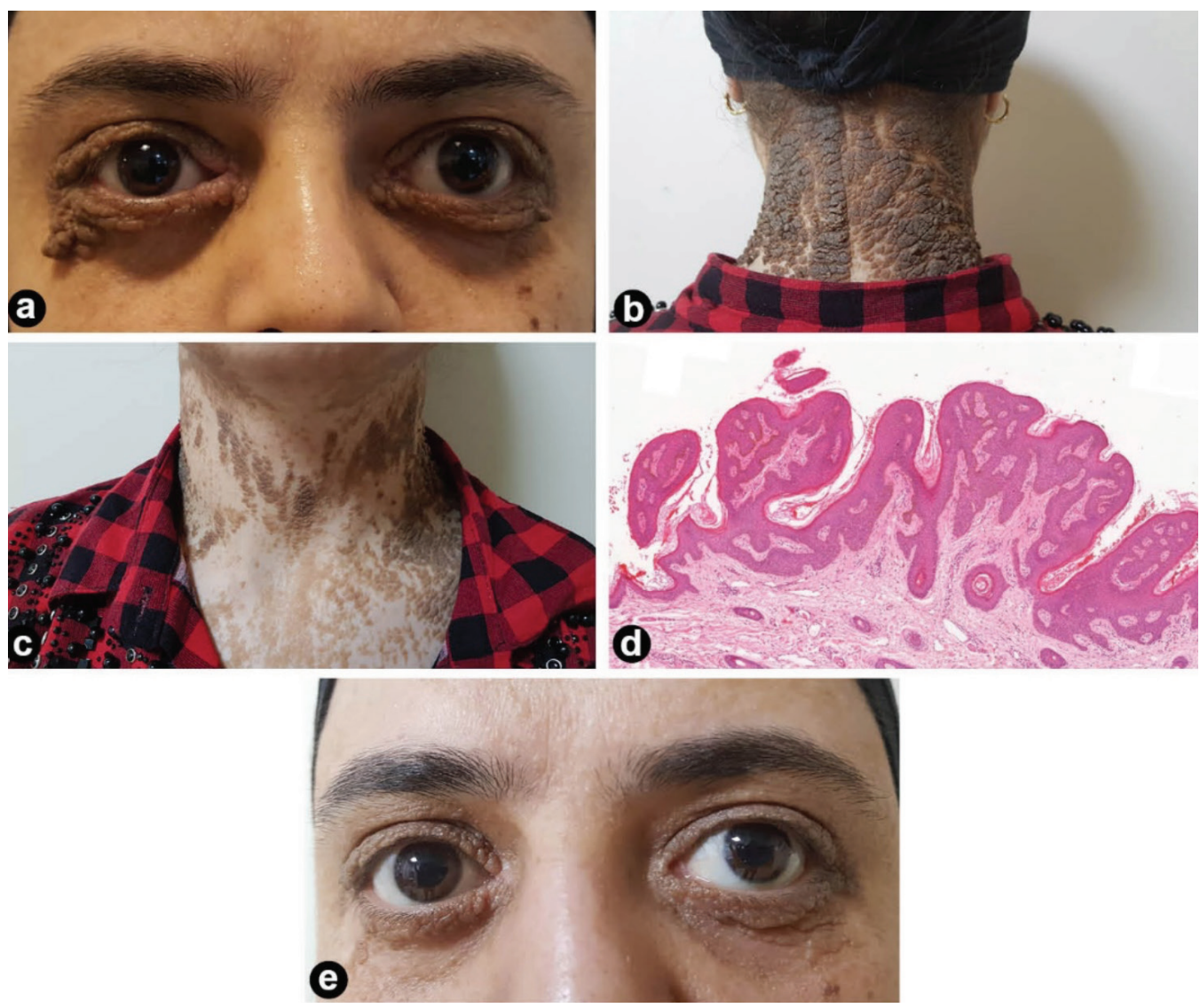

Figure 1. Pigmented verrucous lesions on the eyelids (a) and neck (b, c). d) The epidermis shows papillomatosis, hyperkeratosis, and acanthosis with marked elongation of rete ridges. Mild mononuclear cell infiltrate can be noted surrounding papillary dermal vessels; hematoxylin-eosin X40. e) Photograph taken 4 months after eyelid nevus debulking surgery 
and bifid thumb). ${ }^{9,10}$ In our case, systematized EN was associated only with generalized epilepsy.

Treatment of EN is recommended for cosmetic reasons and to prevent possible malignancy. Numerous treatment options such as excision, cryotherapy, liquid nitrogen, carbon dioxide laser, and topical or intra-lesional glucocorticoids has been used with varying success. Topical and systemic retinoids are other alternative treatment modalities. Oral acitretin therapies have been tried successfully in widespread hyperkeratotic disorders. ${ }^{10}$ Due to the likelihood of malignant transformation in EN, longterm follow-up is suggested for patients with ENS. ${ }^{11}$

Ethics

Informed Consent: Obtained.

Peer-review: Externally peer reviewed.

\section{Authorship Contributions}

Surgical and Medical Practices: M.B.H., A.B., Concept: Ö.B., M.B.H., Design: Ö.B., M.B.H., Data Collection or Processing: Ö.B., M.B.H., A.B., C.C.E., A.O.H., Analysis or Interpretation: Ö.B., A.B., M.B.H., C.C.E.,A.O.H., Literature Search: Ö.B., M.B.H., Writing: M.B.H., A.B., C.C.E., A.O.H.

Conflict of Interest: No conflict of interest was declared by the authors.

Financial Disclosure: The authors declared that this study received no financial support.

\section{References}

1. Vidaurri-de la Cruz H, Tamayo-Sánchez L, Durán-McKinster C, de la Luz Orozco-Covarrubias M, Ruiz-Maldonado R. Epidermal nevus syndromes: clinical findings in 35 patients. Pediatr Dermatol. 2004;21:432-439.

2. Happle R. The group of epidermal nevus syndromes Part I. Well defined phenotypes. J Am Acad Dermatol. 2010;63:1-22.

3. Wolff K. Fitzpatrick's Dermatology in General Medicine. (7th ed). New York: McGraw-Hill Book Co; 2008:876-882.

4. Adams D, Athalye L, Schwimer C, Bender B. A profound case of linear epidermal nevus in a patient with epidermal nevus syndrome. J Dermatol Case Rep. 2011;5:30-33.

5. Sharma R, Singal A, Verma P, Rohatgi J, Sharma S. Epidermal nevus syndrome associated with unusual neurological, ocular, and skeletal features. Indian J Dermatol Venereol Leprol. 2012;78:480-483.

6. Insler MS, Davlin L. Ocular findings in linear sebaceous naevus syndrome. $\mathrm{Br}$ J Ophthalmol. 1987;71:268-272.

7. Rogers M, McCrossin I, Commens C. Epidermal nevi and the epidermal nevus syndrome. A review of 131 cases. J Am Acad Dermatol. 1989;20:476-488.

8. Loff HJ, Bardenstein DS, Levine MR. Systematized epidermal nevi: case report and review of clinical manifestations. Ophthalmic Plast Reconstr Surg. 1994;10:262-266.

9. Chatproedprai S, Wananukul S, Prasarnnaem T, Noppakun N. Epidermal nevus syndrome. Int J Dermatol. 2007;46:858-860.

10. Pandhi D, Reddy BS. A rare association of epidermal nevus syndrome and ainhum-like digital constrictions. Pediatr Dermatol. 2002;19:349-352.

11. Dubois A, Rannan-Eliya S, Husain A, Rajan N, Oliphant T. Squamous cell carcinomas in linear epidermal naevi. Clin Exp Dermatol. 2019;44:238-240. 